\title{
Long Discontinuous Carbon Fibre/Polypropylene Composites for High Volume Structural Applications
}

\author{
L.T. Harper*, D.T. Burn, M. Johnson, N.A. Warrior, \\ School of Mechanical, Materials and Manufacturing Engineering, University of Nottingham, \\ The ITRC Building, University Park, Nottingham, NG7 2RD, UK \\ *Corresponding author, lee.harper@nottingham.ac.uk, Tel: 01159513823
}

\section{Abstract}

A processing route is presented to manufacture discontinuous carbon fibre reinforced polypropylene (CF.PP) composites, using much longer fibre lengths $(25 \mathrm{~mm}$ ) and higher volume fractions (up to $45 \%$ ) than previously reported in the literature. Carbon fibre tows are coated with different ratios of polypropylene, blended with a maleic anhydride coupling agent, to investigate the influence of the interfacial shear strength at the microscale on the macroscale composite properties. Improvements in the tensile performance at the macroscale ( $70 \%$ increase) are not as high as those reported for the interfacial shear strength at the microscale (300\%), following the addition of the coupling agent. Consequently, the tensile strength of the CF.PP material is only $45 \%$ of values reported for carbon fibre/epoxy systems, however, the tensile stiffness is comparable. This demonstrates the potential for using CF.PP for structural applications, following further process optimisation to overcome the current high levels of porosity $\left(3.3 \%\right.$ at $\left.0.45 V_{f}\right)$ to improve the tensile strength.

\section{Keywords}

Compression moulding, discontinuous fibres, thermoplastic, carbon fibre 


\section{Introduction}

Thermoplastic composites used in the automotive industry are typically processed by injection moulding to yield cycle times of less than one minute, but this processing route limits fibre length to less than $1 \mathrm{~mm}$ and therefore restricts the achievable mechanical performance. Long fibre thermoplastics (LFTs) are able to maintain a marginally longer fibre length $(2-3 \mathrm{~mm})$ due to a less aggressive processing route [1], but the main limitation is that in-mould melt flow distances can be quite large, limiting fibre volume fractions to around 25\% [2]. The Dieffenbacher LFT-D process introduces continuous fibre rovings directly into the extrusion unit, which enables fibre lengths of approximately $20-40 \mathrm{~mm}$ to be retained in the component if a compression moulding route is chosen over injection moulding [1]. However, volume fractions are typically limited to $\sim 25 \%$ to ensure adequate flow of the charge within the tool [2].

Clearly, compounding the fibre and matrix together using an extruder limits the achievable fibre length, and the highly viscous nature of the thermoplastic matrix limits the melt flow distance of the polymer and therefore restricts the ceiling fibre volume fraction. In the current paper, a processing route is presented to produce high volume fraction (up to $45 \%$ ), long fibre length ( $25 \mathrm{~mm}$ ) thermoplastic composites using a modified directed carbon fibre preforming process (DCFP) [3]. DCFP is an automated fibre deposition process for creating discontinuous fibre preforms suitable for liquid moulding, and has been successfully used to produce components for the automotive industry [4]. For the current work, carbon fibres are pre-impregnated with a thermoplastic powder to create a towpreg [5], which is then chopped and deposited using a robot to create a net-shape charge, before compression moulding. Pre-coating the tow is designed to reduce the melt-flow distance of the high viscosity polymer during moulding, improving the dispersion of the polymer and reducing the void content. A similar process has been successfully developed to produce carbon fibre / epoxy moulding compounds [6] using low cost industrial grade fibres. 
Polypropylene (PP) is a commodity thermoplastic which is widely used in the automotive industry [7] due to its low cost (typically less than $£ 0.5 / \mathrm{kg}[8]$ ), high toughness and excellent chemical resistance [9]. It is inexpensive, but mechanical properties are typically poor, with tensile stiffness and strength values reported to be less than $2 \mathrm{GPa}$ and $35 \mathrm{MPa}$ respectively $[10,11]$. In addition, PP is nonpolar and has a low chemical affinity with other materials, which means fibre reinforced PP composites commonly fail by fibre pull-out, limiting the effectiveness of the fibre at higher applied loads. This is particularly true for carbon fibre reinforced PP, as the fibre sizing is typically optimised for epoxybased matrices.

Interfacial adhesion can be significantly improved by adding a coupling agent and removing the epoxy-compatible sizing from the carbon, as demonstrated in a previous study by the authors [12]. An interfacial shear strength of 36.2MPa was achieved for a carbon fibre reinforced PP system, compared to $45.9 \mathrm{MPa}$ for a carbon fibre/epoxy benchmark. This paper aims to understand if the improvement in IFSS at the microscale yields higher composite properties at the component macroscale. Carbon fibre reinforced PP plaques are manufactured using much longer fibre lengths $(25 \mathrm{~mm}$ ) and higher volume fractions (up to $45 \%$ ) than previously reported in the literature. A tow coating rig has been developed to produce carbon fibre tows coated with different ratios (by volume) of PP, also enabling the effect of the maleic anhydride coupling agent to be investigated. The mechanical performance of these macroscale composites has been evaluated using tensile, flexural and Charpy impact tests and the data has been compared against a carbon fibre/epoxy benchmark and some commercial LFTs from the literature.

\section{Methodology}

\subsection{Materials}

T700SC-60E 12k tow carbon fibre, supplied by Toray Co., was used for the reinforcement and an isotactic homopolymer PP, Sabic 576P (Sabic Europe B.V., Netherlands), was used as the matrix 
material. The polymer was supplied as pellets, but cryogenic milling was used to produce a powder suitable for the coating process. The pellets were processed into a powder by Goonvean Fibres (Honiton, UK) to a maximum particle size of $90 \mu \mathrm{m}$ (average $65 \mu \mathrm{m}$ ). A maleic anhydride grafted PP coupling agent, G3015 (Eastman, UK), was supplied in granular form and was processed into a powder using a ceramic grinder at ambient temperature. In all cases the coupling agent was mixed with the PP at $2 w t . \%$, based on previous work $[12,13]$.

A powdered epoxy system, DLS 1776 (Hexcel, Duxford, UK), was used as a benchmark thermosetting polymer as it could be melted and cured in a similar manner to the thermoplastics [14], also making it suitable for fibre coating. The epoxy was a B-staged system, enabling it to be heated to $80^{\circ} \mathrm{C}$ during the deposition phase without advancing the cure. The final cure cycle performed in the compression mould tool was at $125^{\circ} \mathrm{C}$ for 23 minutes. The particle size was $99 \%<120 \mu \mathrm{m}$.

\subsection{Tow powder coating rig}

A tow coating rig was designed and manufactured to produce combinations of polymers and fibres at different fibre volume fractions that were not commercially available. The first section of the rig (Figure 1a) consisted of a number of static bars through which the fibre was passed to increase tension and spread the fibres laterally, increasing surface area. The static bars could be adjusted both vertically and horizontally, with eyelets at the front enabling multiple tows to be processed simultaneously. Tow spreading has been used in the literature $[15,16]$ to reduce fibre crimp, but was used here to reduce the melt flow distance of the polymer to enable more intimate contact between the fibres and matrix during consolidation [17].

Once the fibre tow was spread and tensioned, it was passed through a vibrating powder tray (Figure $1 b)$ to be coated. The polymer powder was fluidised by two electric DC motors with variable speed control, mounted on either side of the tray. The fluidisation enabled the tow to pass through the 
powder tray without significantly increasing the tension or causing fibre breakage. The dry thermoplastic powder was attached to the fibres due to electrostatic attraction [18]. The volume fraction of the coated tow could be adjusted by changing the width of the tow (level of spreading) and the angle of the tow between the powder bath and the heating station. After coating, the polymer was melted in the heating section (Figure 2), using two ceramic 650W medium-wave infrared heaters. These were chosen since the selected polymers have spectral absorption curve peaks between 3 and $4 \mu \mathrm{m}$ (a similar wavelength to the output of the infrared heaters), ensuring the polymer was heated efficiently. Whilst the polymer was being melted, it was forced into the tow by two spring-mounted rollers to further improve consolidation. The coated tow was cooled and rewound onto a bobbin at speeds of up to $10 \mathrm{~m} \cdot \mathrm{min}^{-1}$.

\subsection{Plaque preparation}

The coated tow was chopped into $25 \mathrm{~mm}$ lengths using a robot-mounted rotary chopping device [3], which was used to deposit the fibres onto a perforated steel plate over an area of $400 \mathrm{~mm} \times 400$ $\mathrm{mm}$, in order to create a preform. A frame was used to constrain the fibre overspray to ensure the correct areal mass was achieved over the preform area. Approximately $500 \mathrm{~m}$ of coated tow was required for each plaque. A $4 \mathrm{~mm}$ thick aluminium plate was placed over the top of the fibres and the arrangement was transferred to a press (Daniels $160 \mathrm{~T}$ upstroke) at $200^{\circ} \mathrm{C}$ and $0.1 \mathrm{MPa}$ for 5 minutes $\left(80^{\circ} \mathrm{C}\right.$ for the epoxy coated tow) to create a preform. The preform was hot-demoulded and was allowed to cool to ambient. Figure 3 shows the coated fibre stack before preforming.

A $406 \times 406 \mathrm{~mm}$ compression tool mounted in a 160T Daniels upstroke press was used for moulding all panels. Carbon fibre/polypropylene preforms were pre-heated between two polished steel carrier plates, $1.2 \mathrm{~mm}$ thick, which were used to transfer the arrangement to an infrared oven preheated to $230^{\circ} \mathrm{C}$. Thermocouples placed in the centre of the charge indicated that the time to reach the setpoint was approximately 4 minutes, after which the arrangement was transferred to the compression mould tool (including the steel plates). The press was closed at a speed of $100 \mathrm{~mm} \cdot \mathrm{s}^{-1}$ 
and a pressure of 10MPa was applied over the surface of the part for 5 minutes. A typical carbon fibre/PP panel moulded using this procedure is shown in Figure 3(b). Epoxy-based panels were moulded isothermally in the same tool using the same closure speed and pressure. The tool was preheated to $125^{\circ} \mathrm{C}$ and the preform was loaded in directly without the carrier plates. The part was hot-demoulded after 23 minutes and then post-cured at $165^{\circ} \mathrm{C}$ for $2 \mathrm{hrs}$ in a hot-air oven [14].

\subsection{Mechanical test methods}

Tensile testing was carried out in accordance with ISO 572-4/2/2. A modified Type 2 specimen was used, where the length and width of the specimen were $150 \mathrm{~mm}$ and $25 \mathrm{~mm}$ respectively. A distance of $75 \mathrm{~mm}$ was used between the grips, due to limited material availability. All specimens had a nominal thickness of $3 \mathrm{~mm}$ and the test speed was $2 \mathrm{~mm} \cdot \mathrm{min}^{-1}$. A clip on extensometer was used to measure the initial strain of the material to enable the modulus to be calculated, but was removed at $0.5 \%$ strain to avoid damage. At least 10 specimens were tested for each scenario, with specimens that failed at the grips discarded from the analysis.

Flexural testing was carried out in accordance with ISO 14125/I/2. A three-point bending configuration was adopted to characterise the flexural properties, where the radius of the supports was $2 \mathrm{~mm}$ and the radius of the loading roller was $5 \mathrm{~mm}$. The specimen dimensions were $60 \times 25 \times 3$ $\mathrm{mm}$, the span was $48 \mathrm{~mm}$ and the test speed was $2 \mathrm{~mm} \cdot \mathrm{min}^{-1}$.

Charpy impact testing was carried out in accordance with ISO 179-1/2/f/U. Samples were unnotched and the test direction was flatwise, with dimensions of $75 \times 15 \times 3 \mathrm{~mm}$ and span of $60 \mathrm{~mm}$. The striking velocity was $3.46 \mathrm{~m} \cdot \mathrm{s}^{-1}$ and the gravity reading was determined to be $0.05 \mathrm{~J}$, which was used to correct the readings as detailed in ISO 13802. At least 10 specimens were tested for each scenario. 


\subsection{Volume fraction and void content determination}

A Mettler Toledo XS105 Dual Range scale (readability of $0.01 \mathrm{mg}$ at a maximum capacity of $41.0 \mathrm{~g}$, with a repeatability of $0.02 \mathrm{mg}$ ) was used with an Archimedes density fixture, in order to determine the density of each sample from measurements of the weight in water and air at $23^{\circ} \mathrm{C}$. One specimen ( $10 \times 25 \times 3 \mathrm{~mm}$ ) was cut from each end of every tensile coupon, in the regions held by the grips. A wetting agent was applied to the surface of the specimen (Pervitro 75\%) to prevent bubbles occurring when the specimen was lowered into de-ionised water. Prior to testing, specimens were deburred with P600 abrasive paper to remove splintering from the edges caused by cutting.

For the determination of the fibre volume fraction (Vf), densities of $1.18 \mathrm{~g} / \mathrm{cm}^{3}, 0.91 \mathrm{~g} / \mathrm{cm}^{3}$ and 1.80 $\mathrm{g} / \mathrm{cm}^{3}$ were assumed for the epoxy resin [12], the Maleic anhydride grafted PP [19-21] and carbon fibres [22].. The density values from both ends of the specimen were averaged and the coefficient of variation was found to be approximately $0.5-2 \%$ in each case. The volume fraction of the specimen was then calculated based on Equation1:

$$
V_{f}=\frac{\rho_{c}-\rho_{m}}{\rho_{f}-\rho_{m}}
$$

Where $\rho_{\mathrm{c}}$ is the experimental density for each sample and $\rho_{\mathrm{f}}$ and $\rho_{\mathrm{m}}$ are the densities of the fibre and matrix respectively, taken from Table 1 . This method was chosen over alternatives such as acid digestion, because it was fast and simple to perform for the large volume of specimens. The limitation of this method is that it assumes there is no porosity in the sample, which gives rise to artificially low volume fraction values as compared to the target values in Table 1.

Void analysis was performed by optical microscopy, using specimens $(10 \mathrm{~mm} \times 25 \mathrm{~mm} \times 3 \mathrm{~mm})$ cut from the ends of the tensile coupons. Specimens were end-mounted into $\varnothing 40 \mathrm{~mm}$ diameter casting pots using an epoxy adhesive. Clear casting resin was poured into the pots and cured at room 
temperature. Specimens were trimmed to a thickness of $15 \mathrm{~mm}$ and then ground parallel using a surface grinder. Polishing was performed on an orbital Struers DAP-7 machine equipped with an automatic holder (Struers Pedemin-S), in a complementary motion at 125rpm. Five grades of abrasive paper $(120,400,600,1200$ and 4000$)$ were used for five minute periods and the cycle was completed using a flocked wheel with $1 \mu \mathrm{m}$ alumina paste. Specimens were checked under a microscope for scratches and re-polished where necessary.

Micrographs were taken using a Zeiss ${ }^{\circledR}$ Axiolab optical microscope fitted with a monochrome CCD camera. A PC fitted with a Fast Data Translation Framegrabber (DT3155) was used to convert the XY image field into $512 \times 512$ pixels. Image acquisition was automated using a Multicontro| ${ }^{\circledR} 2000$ stage to ensure image alignment and to capture large fields of interest. Void volume fraction was measured using a greyscale thresholding and image analysis technique. Images were processed using the open-source software ImageJ. A macro was created which applied a thresholding mask to isolate the voids in the image. The software determined the total area of voids in terms of the number of pixels within the greyscale threshold.

\section{Results}

\subsection{The effect of coupling agent}

Table 2 summarises the data obtained from mechanical testing for composites moulded at $0.45 \mathrm{Vf}$. The addition of maleic anhydride to virgin PP increased the tensile and flexural strengths by $68 \%$ and $70 \%$ respectively. These percentage increases are lower than the $300 \%$ increase in IFSS reported from microdroplet testing when $2 \% w t$. mPP was added to PP to improve the interfacial performance with carbon fibre [12]. All carbon fibre/PP samples exhibited relatively high void content ( 3 - 4\%) compared to the epoxy samples $(<0.5 \%)$, which dominated the strength properties at high fibre loadings, as previously reported in [23]. The tensile strength of the epoxy benchmark (CF.EP) was 
$119 \%$ higher than the tensile strength of CF.mPP and the flexural strength was $78 \%$ higher than the flexural strength of CF.mPP.

The tensile and flexural moduli both improved with the addition of the maleic anhydride, by $33 \%$ and $34 \%$ respectively. Such large differences in stiffness were unexpected, since the stiffness is principally governed by the elastic properties of the fibre and matrix rather than the interfacial adhesion [24] at low applied strains. Changes in stiffness with the addition of a coupling agent are not typically observed for unidirectional composites [25], however they have been reported for discontinuous fibre composites $[13,26,27]$, which can be attributed to an improvement in compatibility between fibre and matrix up to a critical mPP loading level. A reduction in stiffness was observed by Sanadi et al. [28] when higher mPP levels were used and this was attributed to a change in the molecular morphology of transcrystallisation near the fibre surface. This improvement in tensile stiffness from the addition of mPP means that the tensile stiffness of CF.mPP (28.8 GPa) is within $14 \%$ of the CF.EP samples ( $32.8 \mathrm{GPa})$.

The failure mechanisms of the CF.mPP samples were determined by visual inspection and SEM of the failed samples, and have been compared to the CF.PP and the CF.EP benchmarks. Figure 4 shows the tensile fracture sites for CF.PP, CF.mPP and CF.EP respectively, all moulded at $0.45 V_{f}$. There was a significant difference between the CF.PP and the CF.mPP fracture sites when compared to the CF.EP. The CF.EP sample demonstrated brittle failure characteristics, typical of materials with high interfacial shear strength, with almost all of the fibres still coated in epoxy resin. For the CF.PP and CF.mPP samples there was evidence of fibres pulling away from the matrix, which appeared to be more prominent for the CF.PP samples. This was particularly clear for fibres transverse to the loading direction. Cracks in randomly orientated fibre composites are impeded by the discontinuities, such as fibre cross-overs [29], and either propagate through the matrix or along the interface, depending on the interfacial strength [30]. When the interface is weak, these interfacial cracks propagate along 
the length of the fibre and lead to fibre pull-out [31]. This was demonstrated by the CF.PP samples, as the tows separated during fracture and the ends were flexible and free of matrix. The exposed tows at the fracture sites of the CF.mPP samples were noticeably stiffer and maintained higher tow integrity, with relatively few fibres pulling out from the tows. The CF.EP fracture sites were significantly different to those of the CF.PP and CF.mPP composites, with no flexibility in the exposed tows, confirming excellent adhesion between fibre and matrix. This supports the observations from the microdroplet testing [12], which confirmed that the interfacial shear strength of CF.PP improves with the addition of $2 \mathrm{wt} \%$. mPP, but the resulting interface is still weaker than that of the carbon fibre epoxy.

Figure 4 shows SEM micrographs of tensile fracture sites for CF.PP, CF.mPP and CF.EP. The SEM images confirm that interfacial failure occurred for the CF.PP samples, as the fibres were free of matrix material, indicating fibre pull-out and therefore low interfacial shear strength. Both CF.mPP and CF.EP samples appear to have large amounts of matrix material present on and around the fibres at the fracture site. The addition of maleic anhydride clearly improved the interfacial adhesion between fibre and matrix with the CF.mPP samples showing large lumps of polymer still attached to the surface after testing. The CF.mPP sample showed signs of matrix ductility with plastic deformation clearly visible [32]. The CF.EP failed in a very brittle manner, with fragments of epoxy found around the fracture site. The interface strength was high and the matrix was brittle, therefore cracks propagated through some of the fibre bundles leading to fibre failure.

It is common for a stronger interface to lead to a lower impact strength, as more energy is dissipated through fibre pull-out which results from a weak interface [30, 33]. However, according to Table 1 , the Charpy impact strength of the CF.PP material also improved with the $2 \mathrm{wt} . \%$ addition of mPP. The impact strength increased by $45 \%$ from $56.4 \pm 11 \mathrm{~kJ} / \mathrm{m}^{2}$ to $81.9 \pm 12.5 \mathrm{~kJ} / \mathrm{m}^{2}$. Similar increases have 
been reported for glass fibre/PP discontinuous fibre composites after the fibre sizing had been optimised [34].

\subsection{The effect of fibre volume fraction}

A range of fibre volume fractions have been investigated for the CF.mPP material (up to $45 \% V_{f}$ ), extending beyond the levels typically achieved for LFTs. Tensile, flexural and Charpy impact testing were performed to characterise the mechanical properties, with density measurements taken for each sample to calculate the local fibre volume fraction, in order to normalise the test data to the nominal volume fraction. Examples of stress-strain curves for CF.mPP and CF.EP are presented in Figure 5. The stress-strain relationships confirm that the failure of the CF.mPP samples was more progressive compared to the sudden brittle failure of the CF.EP samples. Progressive failure was more noticeable in lower volume fraction samples, where the strain to failure of the matrix was not significantly reduced by the brittle reinforcing fibres. Consequently, there was a reduction in strainto-failure with increased fibre loading, where the CF45.mPP samples only showed approximately 20\% higher failure strains than the CF.EP samples in Figure 5 (70\% lower than the virgin PP). Toughness is governed by complex interactions between material architecture and properties for discontinuous fibre composites and therefore reductions in strain-to-failure do not necessarily lead to reduced energy absorption. The benefit of the thermoplastic matrix is that it enables a more progressive failure mechanism, demonstrated here for all the CF.mPP samples, which is often preferred from a structural design point of view.

The microstructure of the composites was investigated using optical microscopy and the void content was measured using image analysis software. Figure 6 shows the internal microstructure of carbon fibre/PP composites moulded at volume fractions ranging from $0.15 V_{f}$ to $0.45 V_{f}$. Voids occur in both the inter and intra bundle regions, which suggests that coating the tow with the polymer powder has sufficiently reduced the melt flow distance to enable the spaces between the filaments 
to be impregnated. For the $0.45 V_{f}$ sample, larger voids were concentrated around the perimeter of the fibre bundles, near polymer rich pockets. Voids were not widely observed in areas of high fibre concentration due to local variations in pressure within the mould. Higher volume fraction regions tend to experience the highest pressures, which subsequently reduced the applied load in the low volume fraction regions. The void distribution is therefore linked to the homogeneity of the preform. Figure 7 shows that void content increases as the fibre volume fraction increases. The $0.45 V_{f}$ CF.mPP samples displayed the highest void content of $3.3 \% \pm 1.3$, which was approximately ten times higher than the void content of the epoxy benchmark at the same fibre volume fraction $(0.37 \% \pm 0.1)$. Achieving acceptable levels of fibre wet out is a challenge with polypropylene matrices because of the relatively high viscosity in comparison to the epoxy. This highlights the importance of achieving uniform polymer distribution during the tow powder coating stage to minimise the melt flow distance.

Results for the tensile and flexural moduli of carbon fibre/PP as a function of volume fraction are presented in Figure 8. Results from an analytical model, based on an equivalent inclusion-based approach by Qiu and Weng [35], have been included to contextualise the experimental values. The model has previously been used by the authors to predict the tensile stiffness of mesoscale discontinuous fibre architectures, accounting for the effects of filament bundling $[6,36,37]$. The input parameters for the model are listed in Table 3. Figure 8 indicates that the tensile and flexural moduli increase monotonically throughout the range of volume fractions studied. The experimental tensile moduli are generally within $10 \%$ of the analytical predictions, which suggests that the experimental values are close to the maximum achievable values for the range of volume fractions studied. The tensile modulus is a volume-averaged property and is therefore less affected by void content than more defect sensitive properties such as tensile strength (weakest link theory). There is good stress transfer between the fibres and matrix at low applied strains. The flexural modulus values follow a strong linear relationship $\left(R^{2}=0.99\right)$, and consequently the discrepancy between the 
tensile modulus and flexural modulus increases with increasing fibre loading. A constant span to thickness ratio of $16: 1$ was used for this study, due to limited material availability. A larger span may be required to reduce through-thickness shear stress effects, which can dominate the flexural stresses if the span-to-thickness ratio is too low [38]. Whilst the flexural moduli values may be lower than expected, they confirm that fibre volume fractions as high as $45 \%$ can be successfully achieved for this mescoscale, providing performance gains over plaques with lower fibre content.

The results for the flexural and tensile strength of carbon fibre/PP as a function of volume fraction, are presented in Figure 9. Both tensile and flexural strength increased non-linearly with increasing volume fraction. At approximately $0.25 V_{f}$, both tensile and flexural strength properties appeared to plateau, with tensile strength only increasing by $3 \%$ between 0.25 and $0.35 V_{f}$ and decreasing by $1 \%$ from $0.35-0.45 V_{f}$. The flexural strength showed a similar trend between 0.25 and $0.35 V_{f}$, with only a $0.3 \%$ increase, however between $0.35 V_{f}$ and $0.45 V_{f}$ there was a more significant increase of $19 \%$. The plateau in strength can be attributed to the higher void content [39], which was approximately $3 \%$ by volume for the $0.35 V_{f}$ and $0.45 V_{f}$ samples. In addition, the inter-fibre spacing and therefore the stress transfer efficiency are reduced as the fibre volume fraction increases, resulting in increased risk of fibre breakage due to high local shear stresses induced during processing. This effect was observed for glass fibre/PP LFTs above volume fractions of $0.1 V_{f}[5]$. The current mesoscale architecture of the CF.mPP samples provides better fibre packing compared to the microscale architectures of common LFTs, therefore the strength saturation point occurs at a higher volume fraction $\left(0.25 V_{f}\right)$.

Results from the un-notched Charpy impact testing are presented in Figure 10 as a function of fibre volume fraction. As with the modulus and strength, the Charpy impact strength initially increased with fibre loading. The largest increase in impact strength (107\%) was observed between $0.15 V_{f}$ and $0.25 V_{f}$, reaching a maximum value of $94.7 \pm 13.45 \mathrm{~kJ} / \mathrm{m}^{2}$ at $0.35 V_{f}$. A $13 \%$ reduction in impact 
strength was observed between $0.35-0.45 V_{f}$. Taking experimental variation into account, it appeared that there was relatively little improvement in impact strength with volume fraction above $0.25 V_{f}$, with similar findings reported in the literature $[5,40,41]$. The impact strength in discontinuous fibre composites is largely matrix-dominated [42], where ductile matrices have been shown to dissipate energy through the blunting of sharp crack tips [32]. Despite fibre breakage and pull-out accounting for a large proportion of the fracture energy, there must be sufficient matrix to transfer stresses efficiently. It is understood that fibre fracture leads to stress intensification [43] and cracks therefore propagate through the matrix for high interface strength systems, as opposed to along the interface [31]. This is exacerbated at higher volume fractions as the inter-fibre spacing is reduced and may lead to brittle failure characteristics, therefore the plateau in impact strength is caused by a change in failure mode of the matrix material. Additionally for the CF.mPP systems tested here, low fracture energies at higher volume fractions may have been observed due to the increased likelihood of fibres spanning the width of the sample.

\subsection{Comparison against commercial benchmarks}

The mechanical properties of CF.mPP have been compared to other discontinuous randomly orientated carbon fibre systems, including carbon fibre/epoxy (CF.EP), carbon fibre/PEEK (CF.PEEK) and HexMC (a commercial CF.EP advanced SMC). HexMC was chosen to represent a commercial carbon fibre system suitable for the automotive industry, with CF.PEEK chosen to represent the highest performing thermoplastic composite currently available. It was expected that the HexMC material and experimentally tested CF.EP would perform similarly, and would therefore verify the composite production process due to sharing similar architectures. The comparison between all the materials is presented in Figure 11, with composite properties normalised to $0.45 V_{f}$. The mechanical properties for CF.EP and CF.PEEK were determined experimentally, and values for the HexMC were taken from the literature [14]. 
The tensile stiffness of the CF.mPP was $17 \%$ lower than the stiffness of the CF.EP, which had the highest normalised stiffness (at $0.45 V_{f}$ ) of all of the benchmark materials in Figure 11, but was comparable to the stiffness of the HexMC. The tensile strength of the CF.mPP however, was much lower than all of the other materials. The strength of the CF.PEEK and HexMC were similar (235 $\mathrm{MPa})$, but the tensile strength of the CF.mPP was $57 \%$ lower (101 MPa) at $0.45 V_{f}$. This value is lower than strength values reported in the literature for glass fibre reinforced PP at $0.19 V_{f}[10]$, indicating that stress transfer between fibre and matrix was not taking place efficiently, despite the high interface strengths recorded from the microscale tests. Specific properties $\left(\sigma^{(1 / 2)} / \rho\right.$ and $E^{(1 / 3)} / \rho-$ optimised indices for a plate) are presented in Figure 12 to reflect the property-to-weight ratio. Due to the low density of the PP $\left(910 \mathrm{~kg} / \mathrm{m}^{3}\right)$, the specific stiffness of CF.mPP exceeded all of the other composite materials. The specific tensile strength of CF.mPP however, was lower than the other composite benchmark materials, but was generally within $25 \%$. The comparable CF.EP composite had a $23 \%$ higher specific tensile strength over the CF.mPP, however it was unclear whether this was a direct result of better interfacial adhesions or simply due to lower void content.

Figure 13 shows the performance of CF.mPP compared to other data for carbon and glass discontinuous fibre composites found in the literature $[2,10,11,24,40,44-77]$. The majority of data for discontinuous fibre composites lies between 0.05 and $0.3 V_{f}$, which was primarily due to microscopic (filament-based) fibre architectures being most common for discontinuous fibre composites. Above $0.25 V_{f}$, the stiffness of CF.mPP was comparable to a number of systems tested in the literature. It is worth noting that almost all of the literature uses matrices that are both stronger and stiffer, as well as having better interfacial properties than that seen for CF.mPP. This is highlighted in Figure 13 for volume fractions above $0.25 V_{f}$, where the specific strength of CF.mPP decreases. Deficits in strength may be reduced by further investigation into thermoplastic suitable sizing agents and optimised composite processing. Recent work has demonstrated that the IFSS of CF.mPP can be improved by a further $15 \%$ if the sizing is removed by solvolysis [12], which reduces 
the difference between CF.EP and CF.mPP to within 20\%. Figure 13 also demonstrates that there is a lack of data in the literature between $0.35 V_{f}$ and $0.5 V_{f}$ for thermoplastic systems, and therefore there is a distinct performance gap between discontinuous and continuous fibre composites over this range. By utilising fibre tows and therefore producing discontinuous fibre composites with volume fractions between $0.4 V_{f}-0.5 V_{f}$, properties similar to quasi-isotropic woven composites are anticipated, but with the ability to create much more complex parts with zero wastage due to the inmould flow capability of discontinuous fibre composites.

\section{Conclusions}

The effect of adding a maleic anhydride coupling agent to PP was investigated, as microscale testing had previously showed that the addition of the coupling agent significantly improved the interfacial shear strength. The coupling agent improved all properties that were tested, with the most notable increases seen in tensile and flexural strength. Analysis of the failure sites showed that the CF.PP had almost no matrix left on the fibre, indicating a weak interface and therefore interfacial failure. The CF.mPP samples showed some matrix left on the fibre which indicates a stronger interfacial bond and therefore a mix of matrix and interfacial failure, explaining the increase in strength observed. The CF.mPP and more noticeably CF.PP, displayed ductile failure characteristics due to the high strain-to-failure of the PP matrix. The CF.mPP samples showed comparable stiffness to the CF.EP samples, with the advantage of a more progressive failure compared to the catastrophic failure of the CF.EP. However, the strengths of CF.mPP were significantly lower than an epoxy-based counterpart, which can be partly attributed to higher void content due to non-optimised processing, and partly due to lower interfacial and mechanical properties of the PP compared to the epoxy.

Increasing the fibre volume fraction of CF.mPP samples generally improved all of the mechanical properties tested within this study. The tensile and flexural moduli displayed linear relationships with increasing fibre volume fraction across the volume fraction range. The tensile, flexural and 
impact strengths exhibited linear increases up to approximately $0.25 V_{f}$, after which the properties appeared to plateau. Void content also increased with volume fraction, with voids found in the midplane of the composites, close to the interface between fibre and matrix. This suggested that further reductions in void content, and therefore increases in strength, may be possible by optimising the tow coating and moulding processes.

The $45 \%$ volume fraction CF.mPP composite was compared against commercial materials that are currently used in semi-structural and structural automotive applications. The CF.mPP performed well compared to CF.EP, CF.PEEK and HexMC benchmarks in terms of stiffness, however the strength was lower due to the higher levels of porosity. Higher tensile strengths reported for glass fibre reinforced PP composites highlight that there is an opportunity for strength improvements for CF.mPP composites. Optimisation of pre-heat time, tool temperature and time held at pressure have been shown to reduce void content to less than $1 \%$ for glass fibre/PP systems and can be used in the same way for CF.mPP to minimise the void content observed here.

\section{$5 \quad$ Acknowledgements}

This work was conducted as part of the TARF-LCV project, funded by the UK Engineering and Physical Sciences Research Council, EPSRC (reference EP/1038616/1).

\section{References}

1. Henning, F., H. Ernst, and R. Brüssel, LFTs for automotive applications. Reinforced Plastics, 2005. 49(2): p. 24-33.

2. Krause, W., F. Henning, S. Tröster, O. Geiger, and P. Eyerer, LFT-D-a process technology for large scale production of fiber reinforced thermoplastic components. Journal of Thermoplastic Composite Materials, 2003. 16(4): p. 289-302. 
3. Harper, L.T., T.A. Turner, N.A. Warrior, and C.D. Rudd, Characterisation of random carbon fibre composites from a directed fibre preforming process: The effect of tow filamentisation. Composites Part A: Applied Science and Manufacturing, 2007. 38(3): p. 755-770.

4. CHAVKA, N.G. and J.S. DAHL. P4 preforming technology: Process development utilizing carbon fiber roving. in National Educators' Workshop; update 2001 standard experiments in engineering materials science and technology. 2002.

5. van Hattum, F.W.J., J.P. Nunes, and C.A. Bernardo, A theoretical and experimental study of new towpreg-based long fibre thermoplastic composites. Composites Part A: Applied Science and Manufacturing, 2005. 36(1): p. 25-32.

6. Evans, A.D., C.C. Qian, T.A. Turner, L.T. Harper, and N.A. Warrior, Flow characteristics of carbon fibre moulding compounds. Composites Part A: Applied Science and Manufacturing, 2016. 90: p. 1-12.

7. Jansz, J., Polypropylene in automotive applications, in Polypropylene: An A-Z reference, J. Karger-Kocsis, Editor. 1999, Springer Netherlands: Dordrecht. p. 643-651.

8. Smock, D. Polypropylene Price Forecast for 2015. 3/12/2014; http://www.mypurchasingcenter.com/commodities/commodities-articles/polypropyleneprice-forecast-2015/.

9. Vaidya, U.K. and K.K. Chawla, Processing of fibre reinforced thermoplastic composites. International Materials Reviews, 2008. 53(4): p. 185-218.

10. Thomason, J., M. Vlug, G. Schipper, and H. Krikor, Influence of fibre length and concentration on the properties of glass fibre-reinforced polypropylene: Part 3. Strength and strain at failure. Composites Part A: Applied Science and Manufacturing, 1996. 27(11): p. 1075-1084.

11. THOMASON, J.L. and M.A. VLUG, Influence of fibre length and concentration on the properties of glass fibre-reinforced polypropylene: 1. Tensile and flexural modulus. Composites Part A, 1996. 27A: p. 477-484.

12. Burn, D.T., L.T. Harper, M. Johnson, N.A. Warrior, U. Nagel, L. Yang, and J. Thomason, The usability of recycled carbon fibres in short fibre thermoplastics: interfacial properties. Journal of Materials Science, 2016. 51(16): p. 7699-7715.

13. Wong, K.H., D. Syed Mohammed, S.J. Pickering, and R. Brooks, Effect of coupling agents on reinforcing potential of recycled carbon fibre for polypropylene composite. Composites Science and Technology, 2012. 72(7): p. 835-844.

14. Luchoo, R., L.T. Harper, M.D. Bond, and N.A. Warrior, Net shape spray deposition for compression moulding of discontinuous fibre composites for high performance applications. Plastics Rubber and Composites, 2010. 39(3-5): p. 216-231. 
15. Chen, J.-C. and C.-G. Chao, Numerical simulation and experimental investigation for design of a carbon fiber tow pneumatic spreading system. Carbon, 2005. 43(12): p. 2514-2529.

16. Irfan, M., V. Machavaram, R. Mahendran, N. Shotton-Gale, C. Wait, M. Paget, M. Hudson, and G. Fernando, Lateral spreading of a fiber bundle via mechanical means. Journal of Composite Materials, 2012. 46(3): p. 311-330.

17. Miller, A., C. Wei, and A. Gibson, Manufacture of polyphenylene sulfide (PPS) matrix composites via the powder impregnation route. Composites Part A: applied science and manufacturing, 1996. 27(1): p. 49-56.

18. Iyer, S.R. and L.T. Drzal, Manufacture of Powder-Impregnated Thermoplastic Composites. Journal of Thermoplastic Composite Materials, 1990. 3(4): p. 325-355.

19. SABIC PP 576P - PP homopolymer for injection moulding 28/06/2017]; Available from: http://plasticker.de/recybase/docs/25922 1496827810.pdf

20. Specialist Polymers from Eastman Chemical Company. 28/06/2017]; Available from: http://www.jianqintrade.com/u/bc0bcb18-1980-4e93-b765842ba6e86b48/file/636088565831854608.pdf

21. Eastman Technical Data Sheet - Eastman G-3015 Polymer. Available from: http://ws.eastman.com/ProductCatalogApps/PageControllers/ProdDatasheet PC.aspx?Prod uct=71015384\&sCategoryName=Generic\# ga=2.172567392.218370775.1498766276$\underline{1229859579.1494496440}$

22. TORAYCA - Technical Data Sheet No. CFA-005 28/06/2017]; Available from: http://www.toraycfa.com/pdfs/T700SDataSheet.pdf

23. Van Hattum, F., J. Nunes, and C. Bernardo, A theoretical and experimental study of new towpreg-based long fibre thermoplastic composites. Composites Part A: Applied Science and Manufacturing, 2005. 36(1): p. 25-32.

24. Gupta, V., R. Mittal, P. Sharma, G. Mennig, and J. Wolters, Some studies on glass fiberreinforced polypropylene. Part II: Mechanical properties and their dependence on fiber length, interfacial adhesion, and fiber dispersion. Polymer composites, 1989. 10(1): p. 16-27.

25. Rijsdijk, H., M. Contant, and A. Peijs, Continuous-glass-fibre-reinforced polypropylene composites: I. Influence of maleic-anhydride-modified polypropylene on mechanical properties. Composites Science and Technology, 1993. 48(1-4): p. 161-172.

26. Unterweger, C., J. Duchoslav, D. Stifter, and C. Fürst, Characterization of carbon fiber surfaces and their impact on the mechanical properties of short carbon fiber reinforced polypropylene composites. Composites Science and Technology, 2015. 108: p. 41-47. 
27. Rozman, H.D., G.S. Tay, R.N. Kumar, A. Abusamah, H. Ismail, and Z.A. Mohd. Ishak, Polypropylene-oil palm empty fruit bunch-glass fibre hybrid composites: a preliminary study on the flexural and tensile properties. European Polymer Journal, 2001. 37(6): p. 1283-1291.

28. Sanadi, A.R., D.F. Caulfield, R.E. Jacobson, and R.M. Rowell, Renewable agricultural fibers as reinforcing fillers in plastics: Mechanical properties of kenaf fiber-polypropylene composites. Industrial \& Engineering Chemistry Research, 1995. 34(5): p. 1889-1896.

29. Lindhagen, J. and L. Berglund, Microscopical damage mechanisms in glass fiber reinforced polypropylene. Journal of Applied Polymer Science, 1998. 69(7): p. 1319-1327.

30. Parlevliet, P.P., H.E. Bersee, and A. Beukers, Residual stresses in thermoplastic composites-a study of the literature. Part III: Effects of thermal residual stresses. Composites Part A: Applied Science and Manufacturing, 2007. 38(6): p. 1581-1596.

31. Subramanian, C. and S. Senthilvelan, Development and preliminary performance evaluation of discontinuous fibre reinforced thermoplastic leaf spring. Proceedings of the Institution of Mechanical Engineers, Part L: Journal of Materials Design and Applications, 2009. 223(3): p. 131-142.

32. Cantwell, W. and J. Morton, The significance of damage and defects and their detection in composite materials: a review. The journal of strain analysis for engineering design, 1992. 27(1): p. 29-42.

33. Mukhopadhyay, S., B. Deopura, and R. Alagiruswamy, Interface behavior in polypropylene composites. Journal of Thermoplastic Composite Materials, 2003. 16(6): p. 479-495.

34. Thomason, J. and M. Vlug, Influence of fibre length and concentration on the properties of glass fibre-reinforced polypropylene: 4. Impact properties. Composites Part A: Applied Science and Manufacturing, 1997. 28(3): p. 277-288.

35. Qiu, Y.P. and G.J. Weng, On the application of Mori-Tanaka's theory involving transversely isotropic spheroidal inclusions. International Journal of Engineering Science, 1990. 28(11): p. 1121-1137.

36. Harper, L.T., T.A. Turner, N.A. Warrior, and C.D. Rudd, Characterisation of random carbon fibre composites from a directed fibre preforming process: Effect of fibre length. Composites Part A: Applied Science and Manufacturing, 2006. 37(11): p. 1863-1878.

37. HARPER, L.T., T.A. TURNER, N.A. WARRIOR, and C.D. RUDD, Characterisation of random carbon fibre composites from a directed fibre preforming process: The effect of tow filamentisation. Composites: Part A: Applied Science and Manufacturing, 2007. 38(3): p. 755770. 
38. Harper, L.T., I. Ahmed, R.M. Felfel, and C. Qian, Finite element modelling of the flexural performance of resorbable phosphate glass fibre reinforced PLA composite bone plates. Journal of the Mechanical Behavior of Biomedical Materials, 2012. 15: p. 13-23.

39. EL-Dessouky, H.M. and C.A. Lawrence, Ultra-lightweight carbon fibre/thermoplastic composite material using spread tow technology. Composites Part B: Engineering, 2013. 50: p. 91-97.

40. Bijsterbosch, H. and R. Gaymans, Polyamide 6-long glass fiber injection moldings. Polymer composites, 1995. 16(5): p. 363-369.

41. Fu, S., B. Lauke, E. Mäder, X. Hu, and C. Yue, Fracture resistance of short-glass-fiberreinforced and short-carbon-fiber-reinforced polypropylene under Charpy impact load and its dependence on processing. Journal of Materials Processing Technology, 1999. 89: p. 501507.

42. Peters, S.T., Handbook of composites. 2013: Springer Science \& Business Media.

43. Marston, C., B. Gabbitas, J. Adams, S. Nutt, P. Marshall, and C. Galiotis, Failure characteristics in carbon/epoxy composite tows. Composites Part A: Applied Science and Manufacturing, 1996. 27(12): p. 1183-1194.

44. Goettler, L.A., Mechanical property enhancement in short-fiber composites through the control of fiber orientation during fabrication. Polymer composites, 1984. 5(1): p. 60-71.

45. Yu, H., K. Potter, and M. Wisnom, A novel manufacturing method for aligned discontinuous fibre composites (High Performance-Discontinuous Fibre method). Composites Part A: Applied Science and Manufacturing, 2014. 65: p. 175-185.

46. Akonda, M., C. Lawrence, and B. Weager, Recycled carbon fibre-reinforced polypropylene thermoplastic composites. Composites Part A: Applied Science and Manufacturing, 2012. 43(1): p. 79-86.

47. van Hattum, F. and S. van Breugel, LFT: the future of reinforced thermoplastics? Reinforced Plastics, 2001. 45(6): p. 42-44.

48. Lee, N.-J. and J. Jang, The effect of fibre content on the mechanical properties of glass fibre mat/polypropylene composites. Composites Part A: Applied Science and Manufacturing, 1999. 30(6): p. 815-822.

49. Hassan, A., R. Yahya, A. Yahaya, A. Tahir, and P. Hornsby, Tensile, impact and fiber length properties of injection-molded short and long glass fiber-reinforced polyamide 6, 6 composites. Journal of reinforced plastics and composites, 2004. 23(9): p. 969-986.

50. Kirupanantham, G., Characterisation of discontinuous carbon fibre preforms for automotive applications. 2013, University of Nottingham. 
51. Harper, L.T., T.A. Turner, N.A. Warrior, J.S. Dahl, and C.D. Rudd, Characterisation of random carbon fibre composites from a directed fibre preforming process: Analysis of microstructural parameters. Composites Part A: Applied Science and Manufacturing, 2006. 37(11): p. 21362147.

52. Fu, S.-Y., B. Lauke, E. Mäder, C.-Y. Yue, and X. Hu, Tensile properties of short-glass-fiber-and short-carbon-fiber-reinforced polypropylene composites. Composites Part A: Applied Science and Manufacturing, 2000. 31(10): p. 1117-1125.

53. Botelho, E., M. Rezende, and B. Lauke, Mechanical behavior of carbon fiber reinforced polyamide composites. Composites Science and Technology, 2003. 63(13): p. 1843-1855.

54. Ozkan, C., N.G. Karsli, A. Aytac, and V. Deniz, Short carbon fiber reinforced polycarbonate composites: Effects of different sizing materials. Composites Part B: Engineering, 2014. 62: p. 230-235.

55. McDonnell, P., K. McGarvey, L. Rochford, and C.Ó. Brádaigh, Processing and mechanical properties evaluation of a commingled carbon-fibre/PA-12 composite. Composites Part A: Applied Science and Manufacturing, 2001. 32(7): p. 925-932.

56. Wakeman, M., L. Zingraff, P.-E. Bourban, J.-A. Månson, and P. Blanchard, Stamp forming of carbon fibre/PA12 composites-A comparison of a reactive impregnation process and a commingled yarn system. Composites Science and Technology, 2006. 66(1): p. 19-35.

57. Wakeman, M. and C. Rudd, Compression molding of thermoplastic composites. Comprehensive composite materials, 2000. 2: p. 915-965.

58. Wakeman, M., C. Rudd, T. Cain, R. Brooks, and A. Long, Compression moulding of glass and polypropylene composites for optimised macro-and micro-mechanical properties. 4: Technology demonstrator-a door cassette structure. Composites science and technology, 2000. 60(10): p. 1901-1918.

59. JACOB, G.C., J.M. STARBUCK, J.F. FELLERS, and S. SIMUNOVIC, Effect of fiber volume fraction, fiber length and fiber tow size on the energy absorption of chopped fiber-polymer composites. Polymer Composites, 2005. 26(3): p. 293-305.

60. Güllü, A., A. Özdemir, and E. Özdemir, Experimental investigation of the effect of glass fibres on the mechanical properties of polypropylene (PP) and polyamide 6 (PA6) plastics. Materials \& design, 2006. 27(4): p. 316-323.

61. Truckenmüller, F. and H.G. Fritz, Injection molding of long fiber-reinforced thermoplastics: A comparison of extruded and pultruded materials with direct addition of roving strands. Polymer Engineering \& Science, 1991. 31(18): p. 1316-1329. 
62. Denault, J., T. Vu-Khanh, and B. Foster, Tensile properties of injection molded long fiber thermoplastic composites. Polymer composites, 1989. 10(5): p. 313-321.

63. Templeton, P., Strength predictions of injection molding compounds. Journal of reinforced Plastics and Composites, 1990. 9(3): p. 210-225.

64. Johanson, K., L.T. Harper, M.S. Johnson, and N.A. Warrior, Heterogeneity of discontinuous carbon fibre composites: Damage initiation captured by Digital Image Correlation. Composites Part A: Applied Science and Manufacturing, 2015. 68: p. 304-312.

65. Rahmanian, S., K. Thean, A. Suraya, M. Shazed, M.M. Salleh, and H. Yusoff, Carbon and glass hierarchical fibers: Influence of carbon nanotubes on tensile, flexural and impact properties of short fiber reinforced composites. Materials \& Design, 2013. 43: p. 10-16.

66. Eguémann, N., L. Giger, K. Masania, C. Dransfeld, F. Thiebaud, and D. Perreux. Processing of characterisation of carbon fibre reinforced PEEK with discontinuous architecture. in 16th European conference on composite materials, Seville, Spain. 2014.

67. Li, M., X. Wen, J. Liu, and T. Tang, Synergetic effect of epoxy resin and maleic anhydride grafted polypropylene on improving mechanical properties of polypropylene/short carbon fiber composites. Composites Part A: Applied Science and Manufacturing, 2014. 67: p. 212220.

68. Karsli, N.G. and A. Aytac, Effects of maleated polypropylene on the morphology, thermal and mechanical properties of short carbon fiber reinforced polypropylene composites. Materials \& Design, 2011. 32(7): p. 4069-4073.

69. Bowland, C. A formulation study of long fiber thermoplastic polypropylene (Part 2): the effects of coupling agent type and properties. in SPE Automotive and Composites Division: 9th Annual Automotive Composites Conference and Exhibition. 2009.

70. Chaudhari, R., M. Reif, O. Geiger, F. Henning, A. Diehl, and A. Terenzi, E-COAT SUSTAINABLE LONG-FIBER THERMOPLASTIC COMPOSITES FOR STRUCTURAL AUTOMOTIVE APPLICATIONS. Advances in Thermoplastic Composites, 2008. 1: p. 208-222.

71. Paesano, A., D. Cohee, and G. Palmese, Carbon-fiber reinforced thermoplastic materials for rigidizable space systems. Journal of Thermoplastic Composite Materials, 2003. 16(2): p. 139-170.

72. Piggott, M., M. Ko, and H. Chuang, Aligned short-fibre reinforced thermosets: experiments and analysis lend little support for established theory. Composites science and technology, 1993. 48(1-4): p. 291-299.

73. Edwards, H. and N. Evans, A method for the production of high quality aligned short fibre mats and their composites. ICCM-3, Paris, 1980: p. 1620-35. 
74. SUCH, M., C. WARD, and K. POTTER, Aligned discontinuous fibre composites: a short history. Journal of Multifunctional Composites, 2014. 2(3).

75. Stoeffler, K., S. Andjelic, N. Legros, J. Roberge, and S.B. Schougaard, Polyphenylene sulfide (PPS) composites reinforced with recycled carbon fiber. Composites Science and Technology, 2013. 84: p. 65-71.

76. Turner, T.A., L.T. Harper, N.A. Warrior, and C.D. Rudd, Low cost carbon-fibre based automotive body panel systems - a performance and manufacturing cost comparison. Journal of Automobile Engineering - Proceedings of the Institution of Mechanical Engineers Part D, 2008. 222(1): p. 53-64.

77. Bowland, C. A formulation study of long fiber thermoplastic polypropylene (Part 1): the effects of coupling agent, glass content \& resin properties on the mechanical properties. in SPE Automotive and Composites Division: 8th Annual Automotive Composites Conference and Exhibition. 2008. 


\section{Tables}

Table 1: Global fibre volume fraction measurements obtained from density measurements of tensile test specimens. The densities of the constituent materials were obtained from manufacturer's data sheets.

\begin{tabular}{lcll}
\hline & $\begin{array}{c}\text { Polymer density } \\
\left(\mathrm{g} / \mathrm{cm}^{3}\right)\end{array}$ & \multicolumn{2}{c}{ Volume Fraction } \\
\cline { 3 - 4 } & 0.913 & 0.14 & CoV $(\%)$ \\
\hline CF15.mPP & 0.913 & 0.25 & 4.4 \\
CF25.mPP & 0.913 & 0.34 & 2.8 \\
CF35.mPP & 0.913 & 0.43 & 0.9 \\
CF45.mPP & 1.181 & 0.44 & 1.2 \\
CF45.EP & & & \\
\hline
\end{tabular}

Table 2: Mechanical property data recorded for carbon fibre/polypropylene samples with (CF.mPP) and without (CF.PP) a coupling agent, compared to a carbon fibre/epoxy (CF.EP) benchmark all at $0.45 V_{f}$.

\begin{tabular}{lcccccc}
\hline \multirow{2}{*}{ Property } & \multicolumn{2}{c}{ CF.PP } & \multicolumn{2}{c}{ CF.mPP } & \multicolumn{2}{c}{ CF.EP } \\
\cline { 2 - 7 } & $\overline{\mathrm{X}}$ & $\mathrm{s}$ & $\overline{\mathrm{X}}$ & $\mathrm{s}$ & $\overline{\mathrm{X}}$ & $\mathrm{s}$ \\
\hline Tensile Modulus (GPa) & 21.63 & 3.76 & 28.77 & 5.7 & 32.8 & 3.95 \\
Tensile Strength (MPa) & 60.13 & 10.13 & 100.82 & 19.51 & 220.57 & 29.7 \\
Flexural Modulus (GPa) & 13.72 & 1.89 & 18.35 & 3.06 & 19.56 & 1.7 \\
Flexural Strength (MPa) & 105.18 & 6.19 & 179.15 & 15.99 & 320.15 & 12.1 \\
Charpy Impact (kJ/m²) & 56.37 & 10.96 & 81.93 & 12.5 & 66.1 & 6.07 \\
Void Content (\%) & 3.47 & 2.12 & 3.34 & 1.29 & 0.36 & 0.12 \\
\hline
\end{tabular}

Table 3: Input parameters for analytical modelling of CF.mPP. Fibre values taken from [35] and polymer values were determined experimentally.

\begin{tabular}{l|l}
\hline Tensile modulus - mPP (GPa) & 1.92 \\
Poisson's ratio - mPP & 0.38 \\
Shear modulus - mPP (GPa) & 0.51 \\
& \\
Tow size & 12000 \\
Filament diameter ( $\mu \mathrm{m})$ & 7.0 \\
Fibre length (mm) & 25.0 \\
Plane strain bulk modulus - fibre (GPa) & 20.20 \\
Cross modulus - fibre (GPa) & 12.10 \\
Axial modulus under axial strain - fibre (GPa) & 234.20 \\
Transverse shear modulus - fibre (GPa) & 8.10 \\
Axial shear modulus - fibre (GPa) & 10.0 \\
\hline
\end{tabular}




\section{Figures}
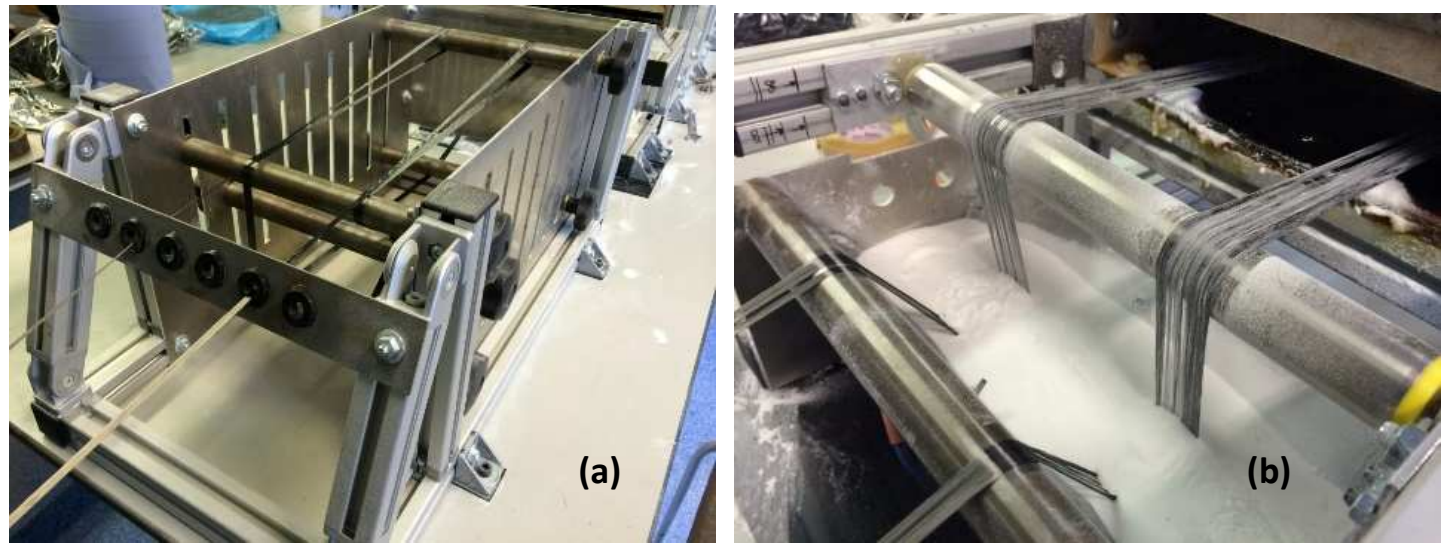

Figure 1 - (a) Spreading section of the tow coating rig consisting of a number of static bars to increase tension and spread the fibre bundles. (b) Power tray section showing spreading and coating of the fibres with polypropylene powder.

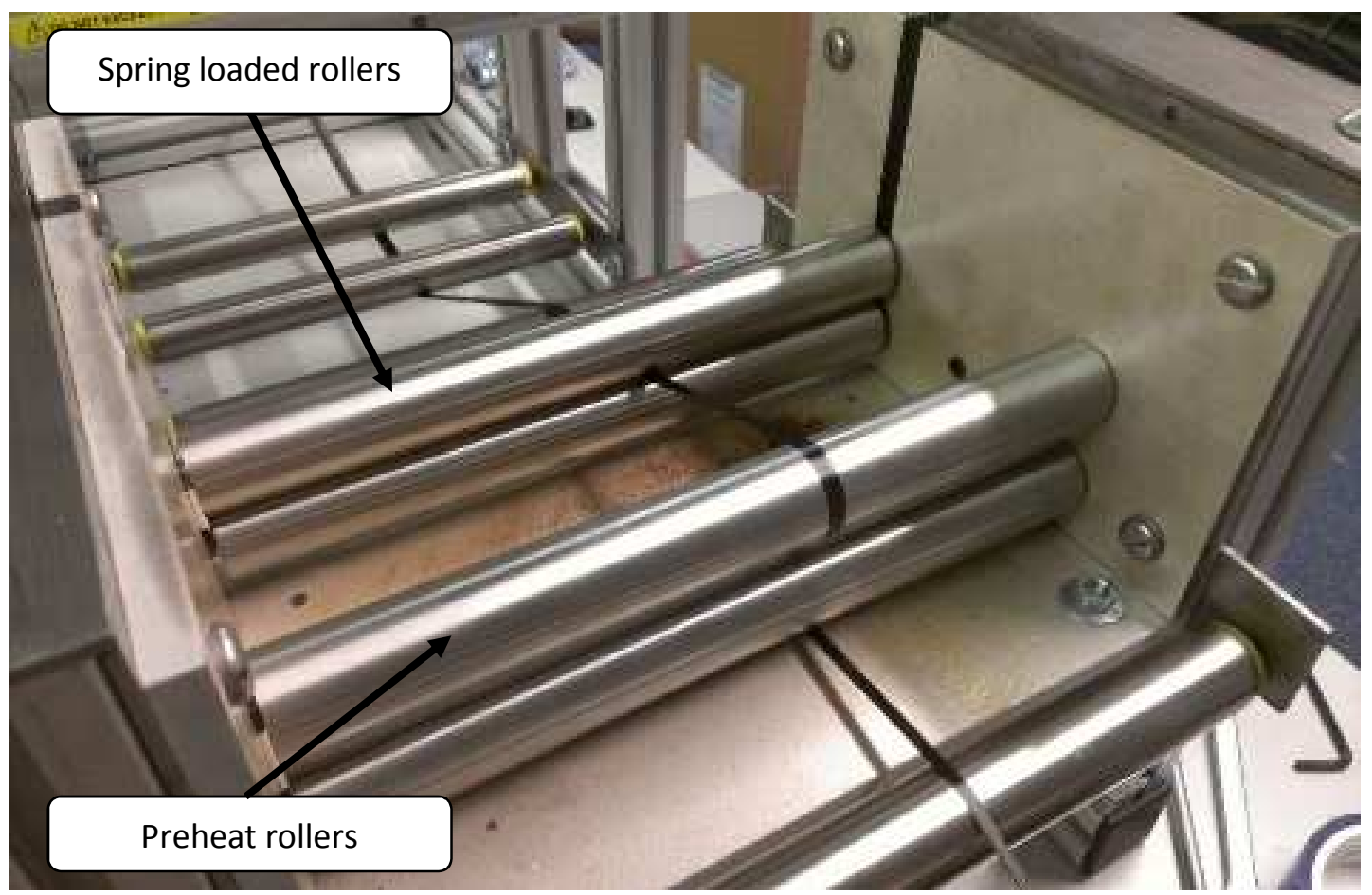

Figure 2 - Heating section of tow coating rig showing preheat and consolidation rollers to ensure maximum impregnation of the polymer into the tows (heaters and side insulation removed for photo) 

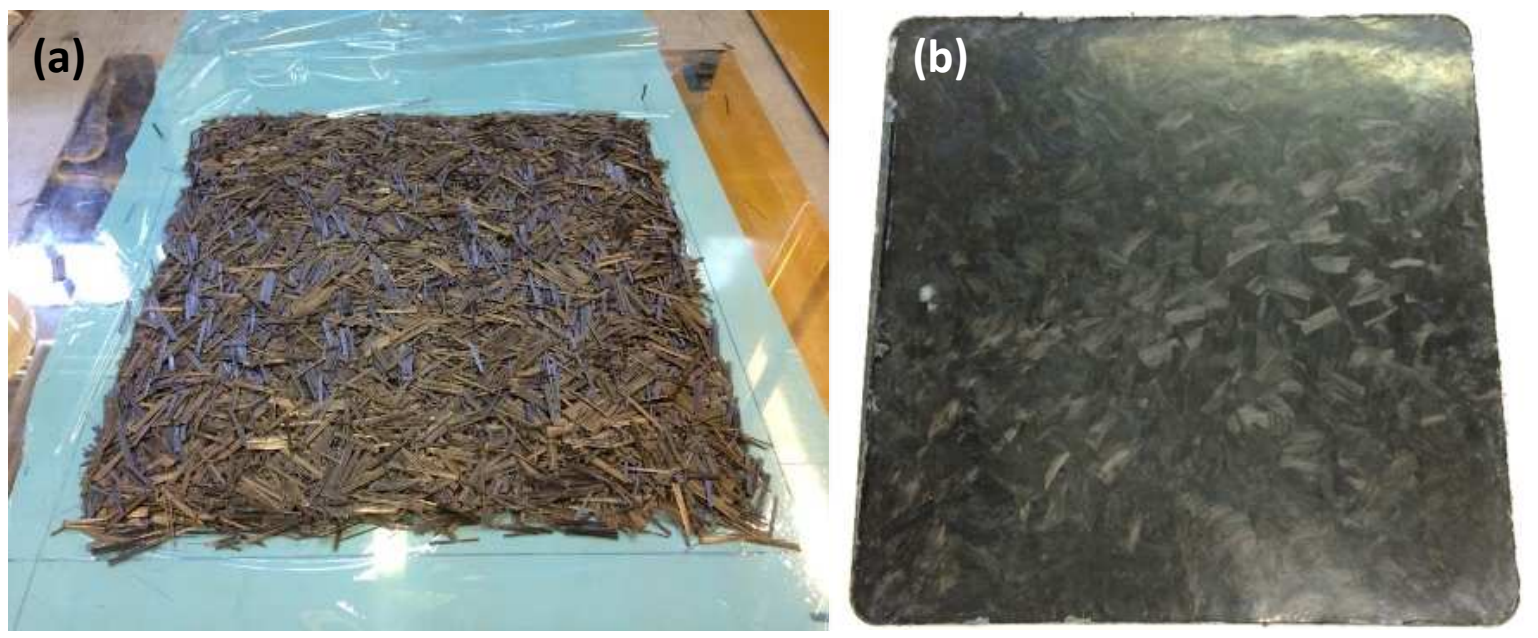

Figure 3 - (a) $406 \mathrm{~mm} \times 406 \mathrm{~mm}$ CF.PP material before consolidation, (b) carbon fibre/polypropylene panel moulded at $0.45 V_{f}$
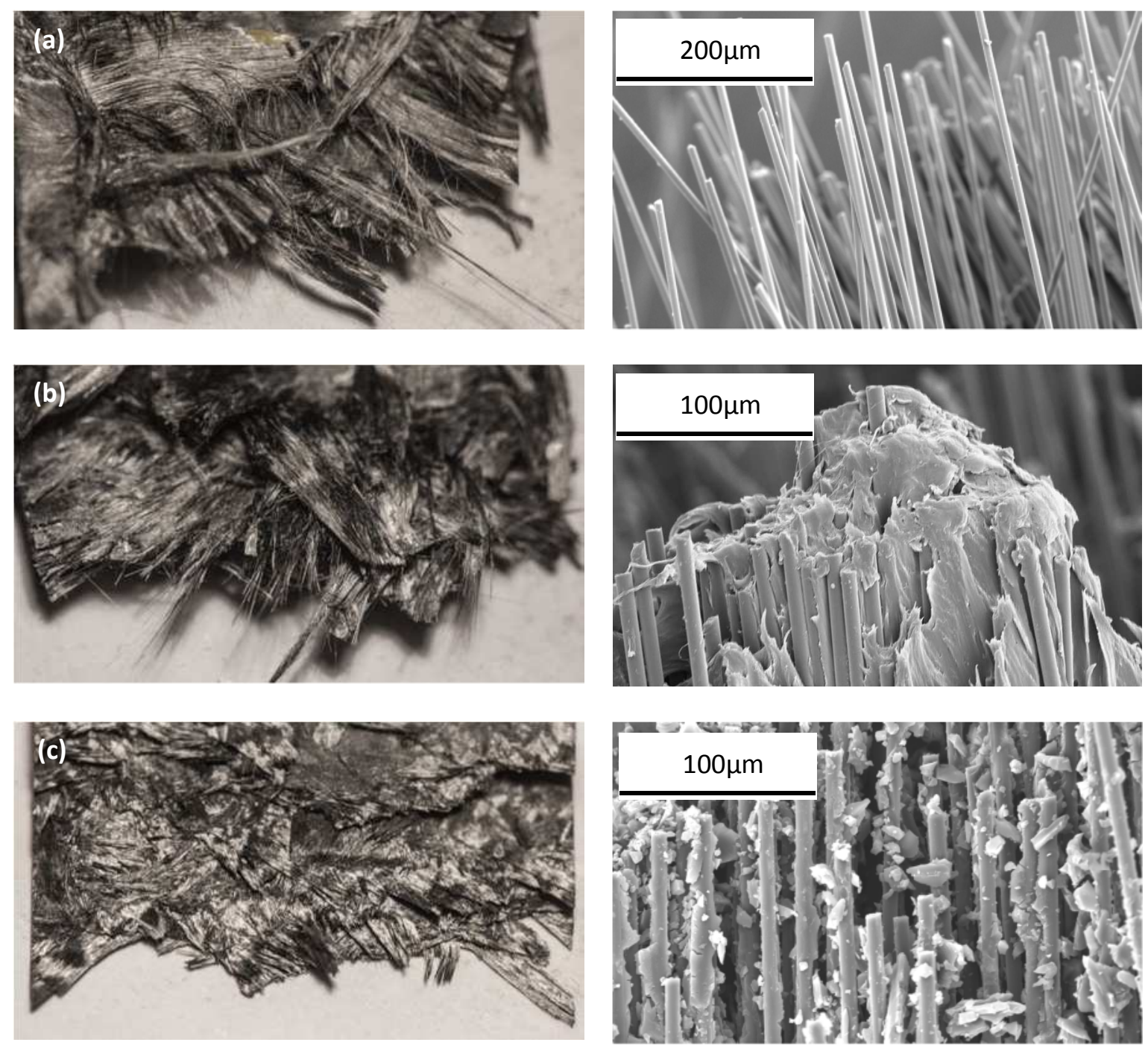

Figure 4 - (Left) Tensile fracture sites (Right) SEM micrographs of tensile fracture sites. (a) CF.PP, (b) CF.mPP and (c) CF.EP all moulded at $0.45 V_{f}$ 


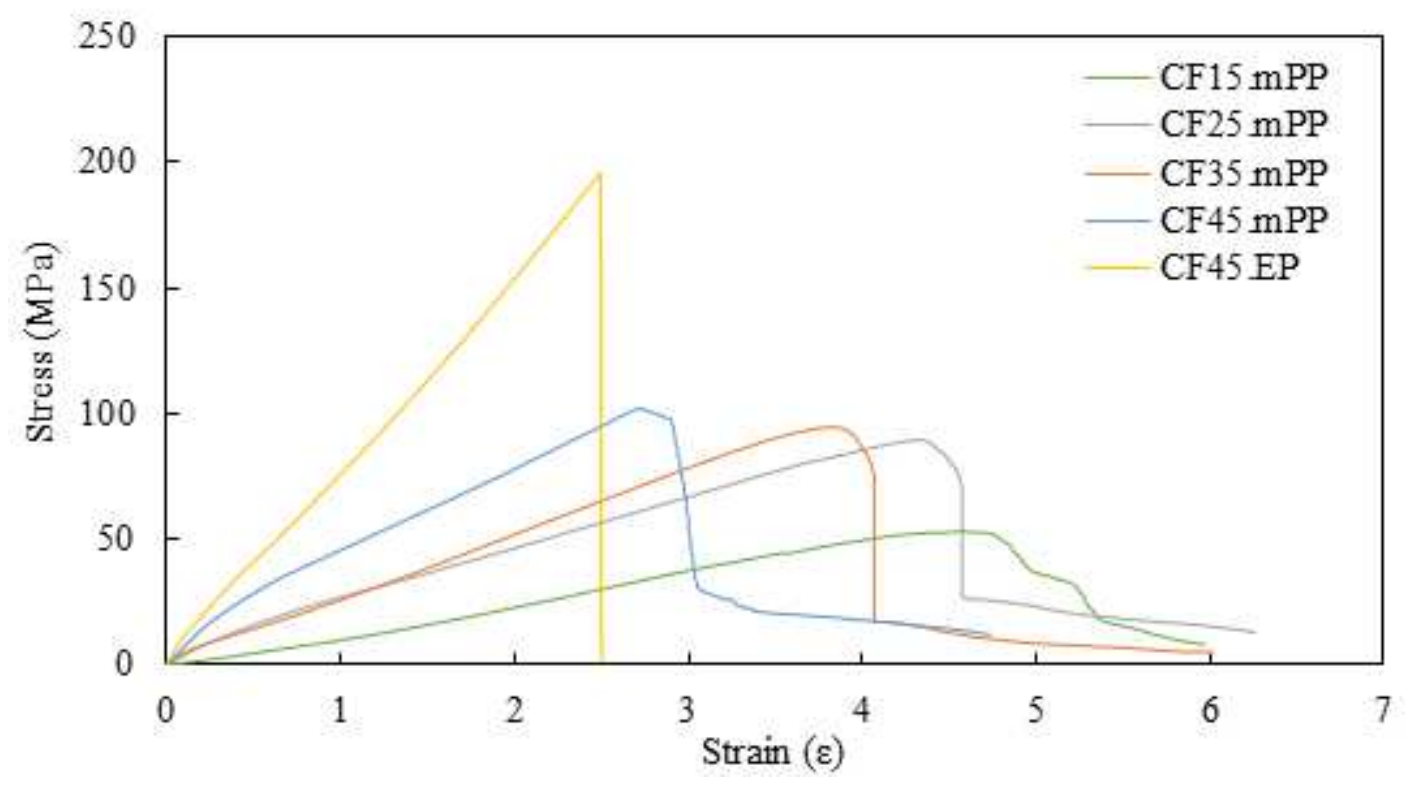

Figure 5 - Examples of tensile stress-strain curves for a range of fibre volume fractions. A carbon fibre/epoxy benchmark is included with a volume fraction of $45 \%$. 


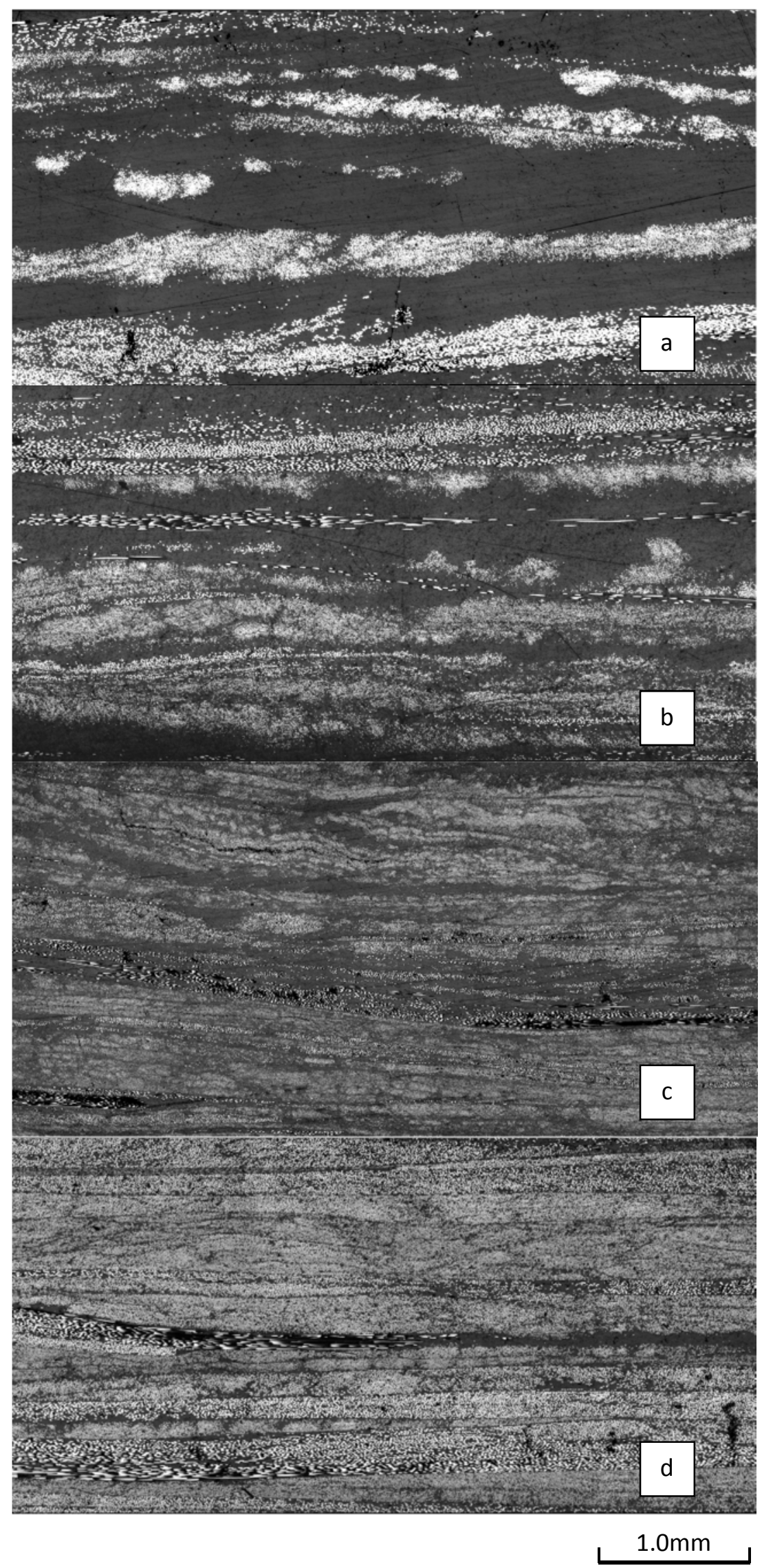

Figure 6 - Optical microscopy images of CF.mPP composites moulded at a range of different fibre volume fractions: a) CF15.mPP, b) CF25.mPP, c) CF35.mPP and d) CF45.mPP 


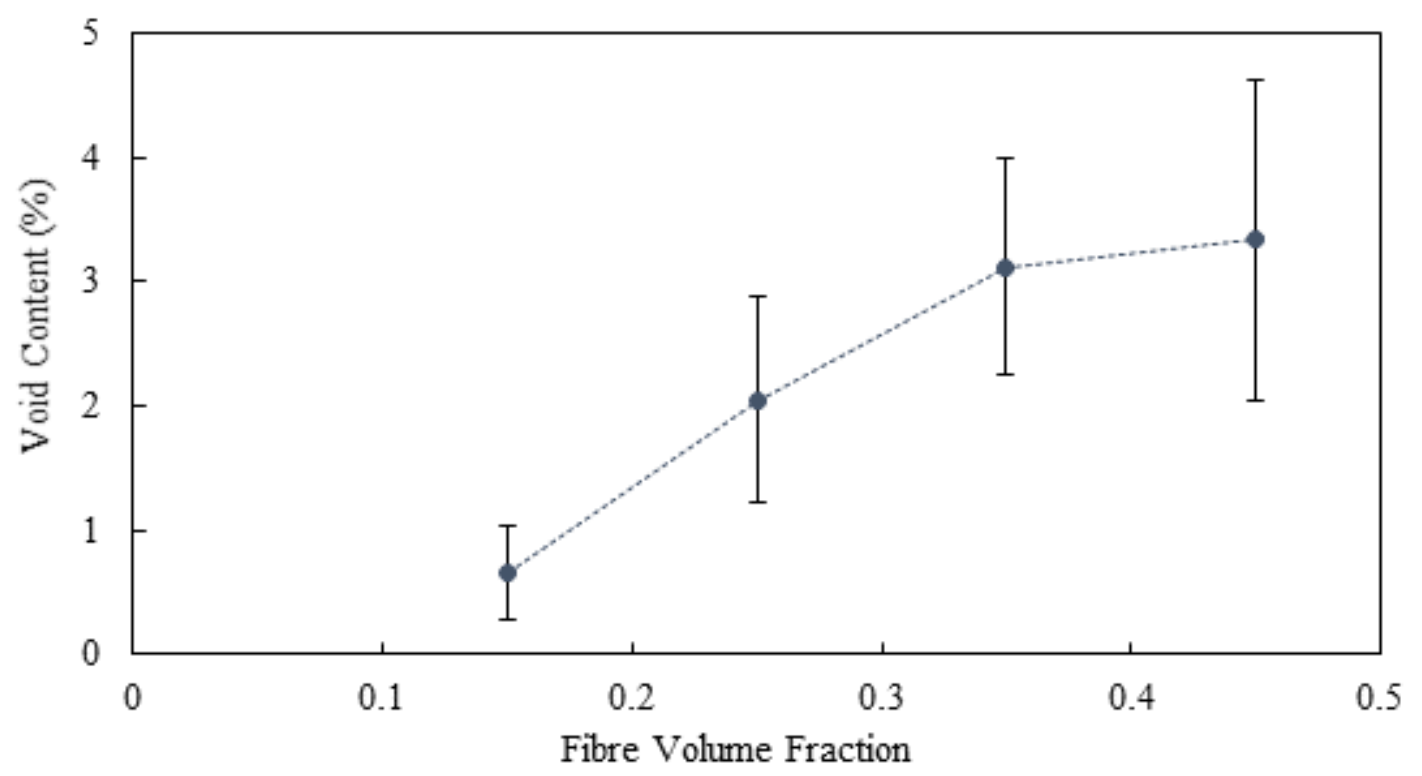

Figure 7 - Void content for CF.mPP samples as a function of fibre volume fraction (error bars are standard deviation)

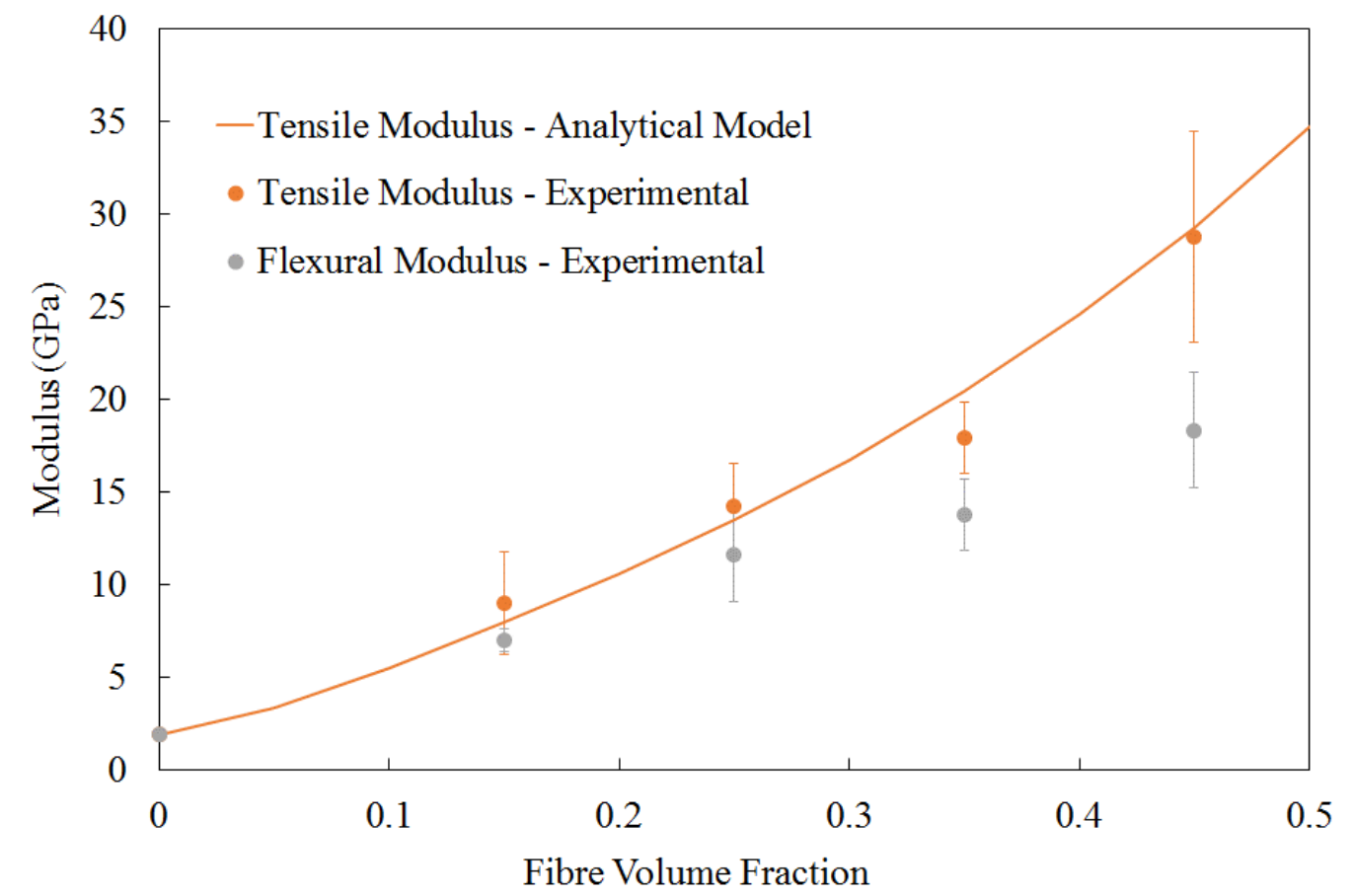

Figure 8 - Tensile and flexural moduli as a function of fibre volume fraction for CF.mPP. 


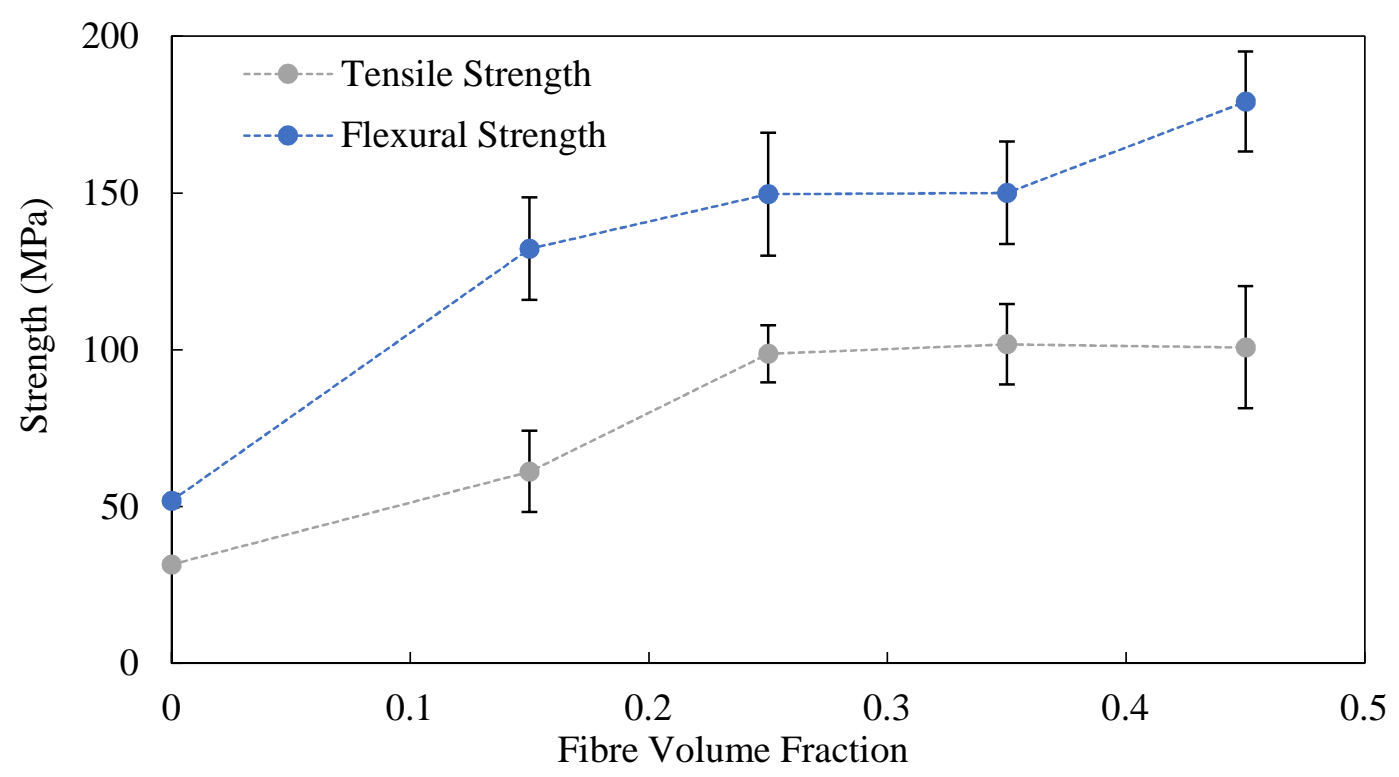

Figure 9 - Tensile and flexural strength as a function of fibre volume fraction for CF.mPP

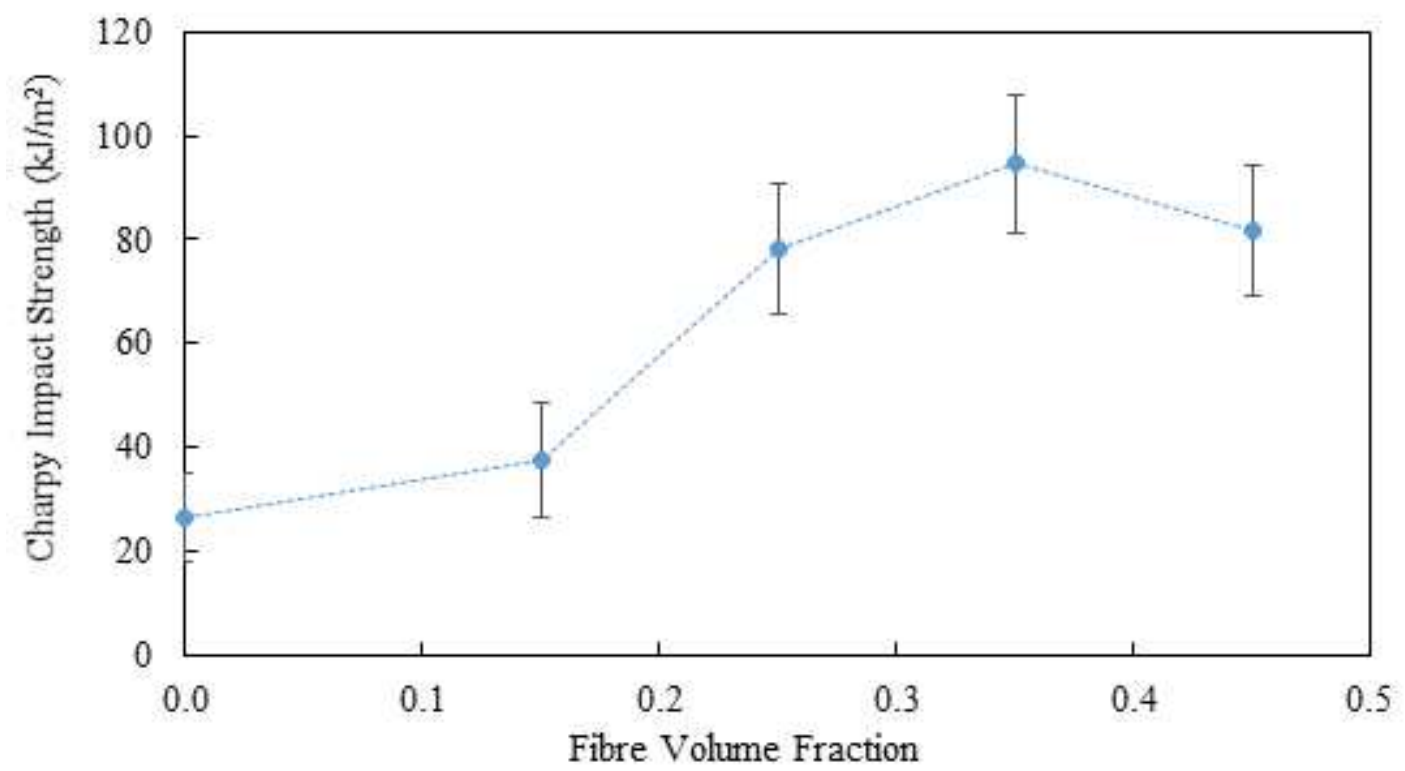

Figure 10 - Charpy impact data for carbon fibre/polypropylene as a function of volume fraction 


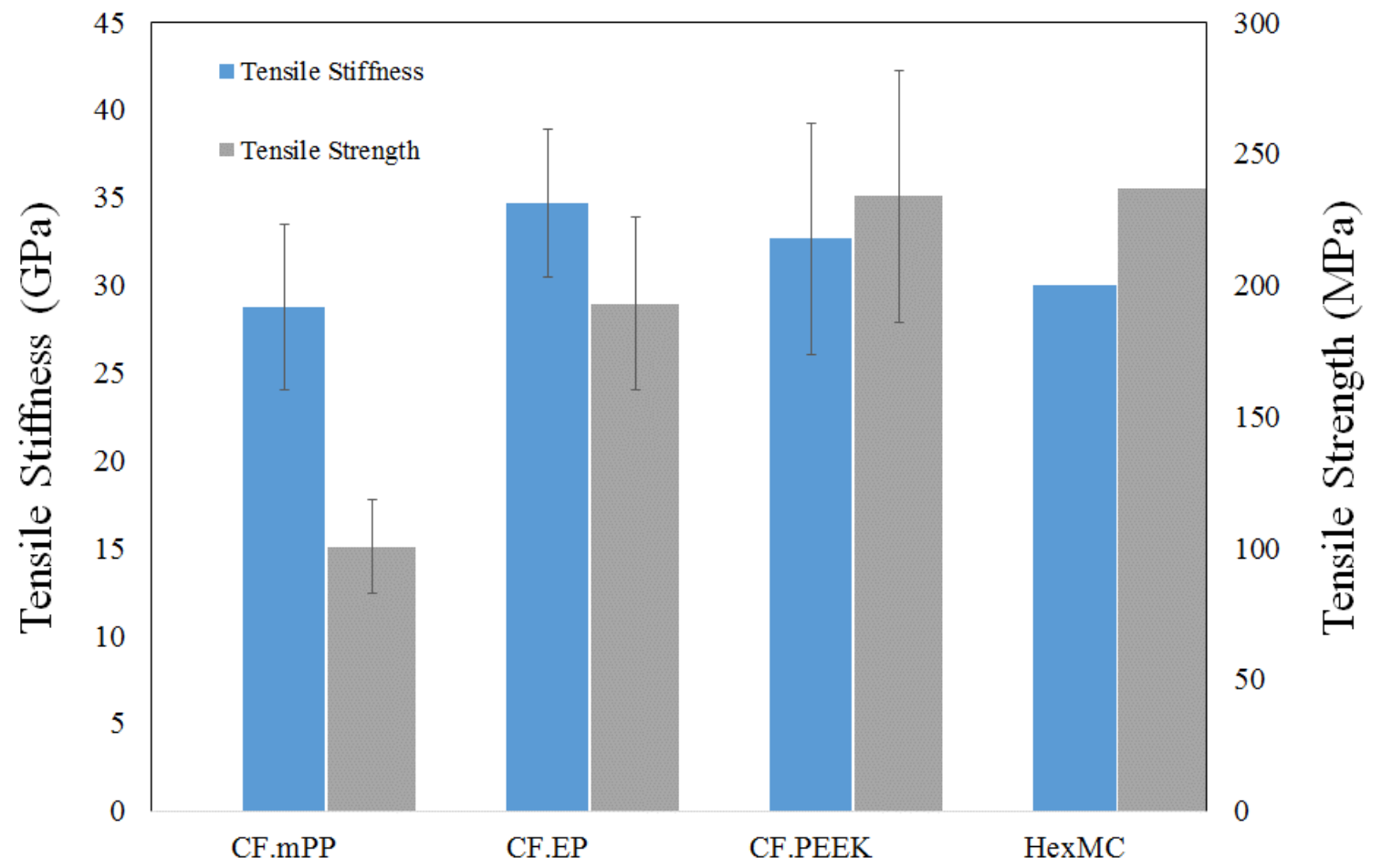

Figure 11 - Comparison of tensile properties of CF.mPP and various carbon fibre benchmark materials. Values have been normalised to $0.45 V_{f}$ for comparison purposes

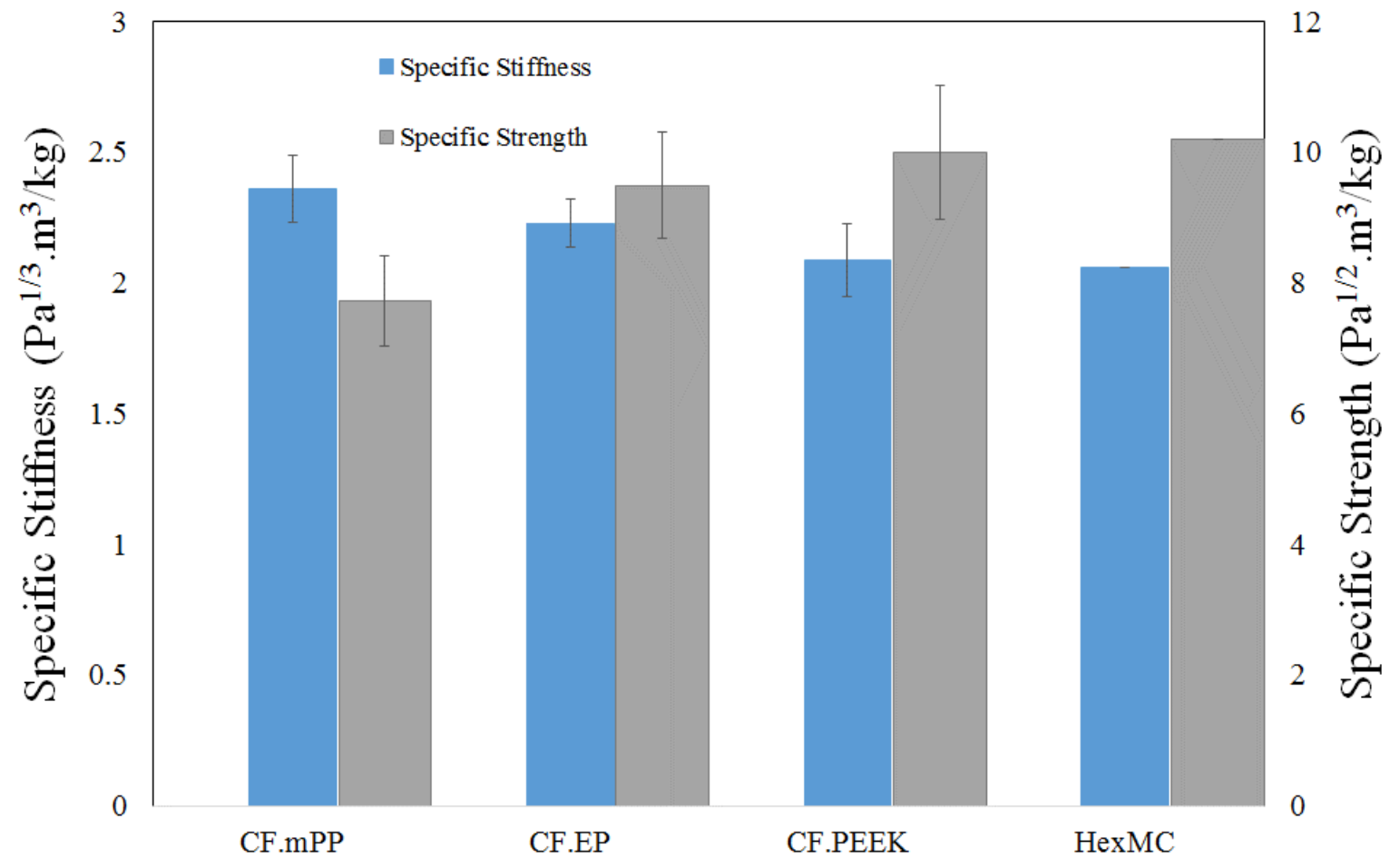

Figure 12 - Comparison of specific tensile properties of CF.mPP and various carbon fibre benchmark materials. Values have been normalised to $0.45 \mathrm{Vf}$ for comparison purposes 

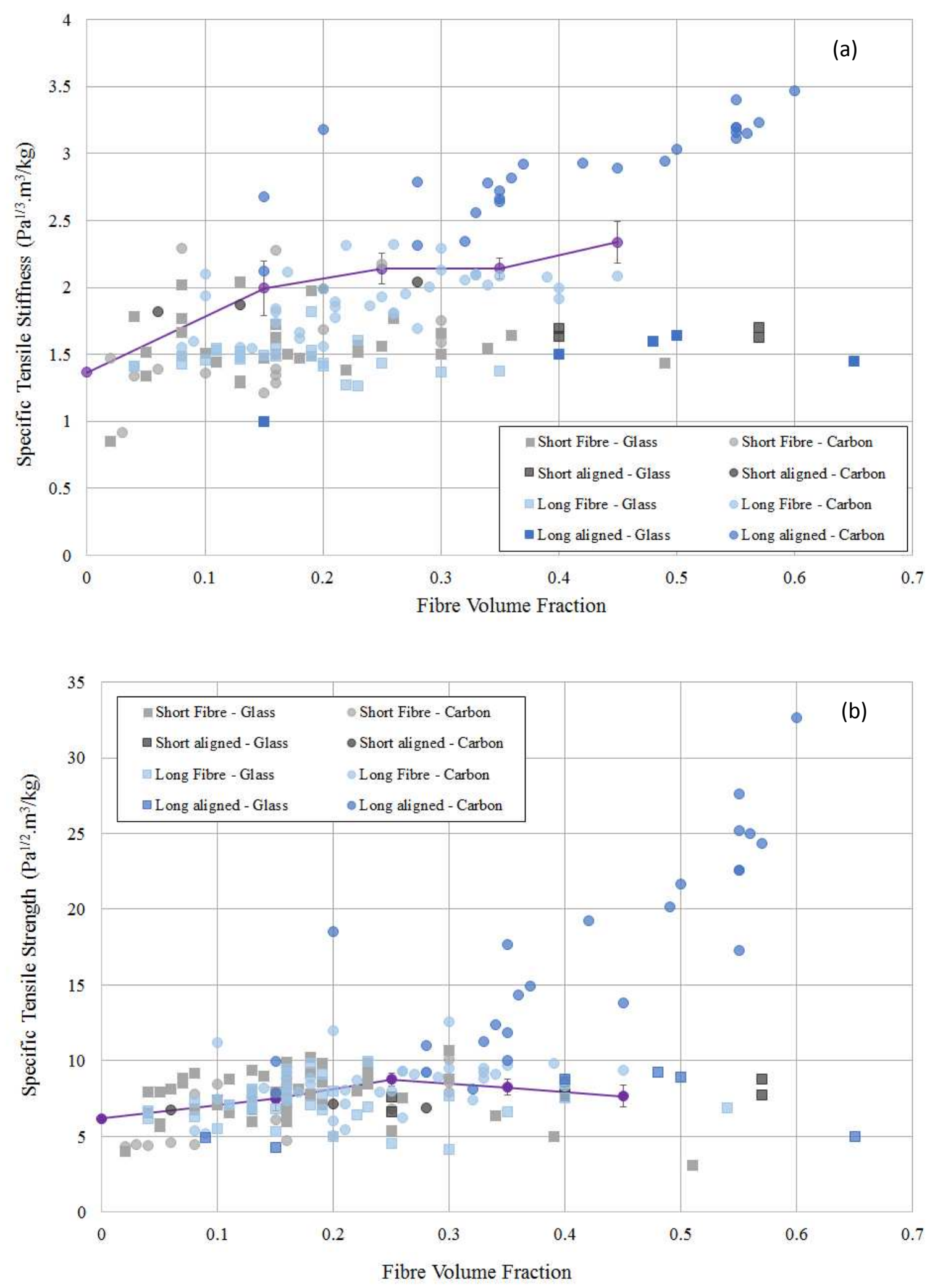

Figure 13 - (a) CF.mPP specific stiffness and (b) specific strength data (solid lines) compared to literature values for discontinuous carbon and glass fibre composites (Data taken from $[2,10,11,24$, 40, 44-77]) 